\title{
AGRONEGÓCIO EM ÁREAS DE FRONTEIRA: UMA RELAÇÃO POSSÍVEL
}

Resumo: Áreas de fronteira são, historicamente, caracterizadas pelo desenvolvimento de atividades terciárias. O desenvolvimento econômico de tais espaços esteve, desde a gênese da maior parte das fronteiras brasileiras, atrelado a atividades comerciais. Com características singulares em relação a seus Estados nacionais, as fronteiras não contaram com uma agropecuária evidenciada, o que fortaleceu a ideia de que a atividade não faz parte da dinâmica econômica desta porção do país. No entanto, algumas áreas de fronteira tem no agronegócio uma atividade importante, a exemplo do município gaúcho de Uruguaiana. A partir disso e com base em análise bibliográfica, levantamento de dados e pesquisa de campo, 0 objetivo deste trabalho é de apresentar e discutir a dinâmica do agronegócio em Uruguaiana. Verificou-se que o município tem na rizicultura e na pecuária suas principais atividades econômicas, com ampliação da rizicultura nas últimas décadas.

Palavras-chave: Fronteira. Agronegócio. Uruguaiana.

\section{AGRIBUSINESS IN FRONTIER: A POSSIBLE RELATIONSHIP}

Abstract: Border areas are historically characterized by the development tertiary activities. The economic development of that spaces has been, since the genesis of most brazilian borders, linked to commercial activities. With differents characteristics in relation of others parts of national states, the frontiers didn't count an intensive agriculture and livestock, which strengthened the ideia that the activities is not part of economic dynamic of this part of country. However, some border areas have important activity in agribusiness, such as the municipality of Uruguaiana in Rio Grande do Sul. From this and based in bibliographical analysis and field research, the objective of this work is present and discuss the agribusiness dynamics in Uruguaiana. It was verified that the municipality has in the rice cultivation and livestock the main economic activities, with expansion of rice cultivation in the last decades.

Keywords: Frontier. Agribusiness. Uruguaiana.

\section{AGRONEGOCIO EN ÁREAS DE FRONTERA: UNA RELACÍON POSIBLE}

Resumen: Áreas de frontera son históricamente caracterizadas por el desarollo de actividades terciarias. El desarrollo económico de estos espacios estuvo, desde la génesis de la mayor parte de las fronteras brasileñas, vinculado a actividades comerciales. Con características singulares en relación a sus Estados nacionales, las fronteras no contaron con uma agropecuaria intensina, lo que fortaleció la idea de que la actividad no participa dela dinámica ecnómica de esta porción del país. Sin embargo, algunas areas de frontera tienen en el agronegocio una actividad importante, a ejemplo del municipalidad de Uruguaiana en Rio Grande del Sul. A partir de eso y con base en análisis bibliográfico e investigación de campo, el objectivo de este trabajo es presentar y discutir la dinámica del agronegocio en Uruguaiana. Se verificó que el municipalidad tiene en la rizicultura y ganaderia sus

1 Universidade Estadual de Londrina, Departamento de Geociências, Londrina, Brasil, claudiaheloiza@yahoo.com.br, https://orcid.org/0000-0002-7537-0749 
principales actividades económicas, com ampliación de la rizucultura en las últimas décadas.

Palabras clave: Frontera. Agronegocio. Uruguaiana.

\section{Introdução}

A origem da palavra fronteira, de acordo com Machado (1998), não estava associada a um conceito legal, ou seja, não era considerado conceito político ou intelectual. Surgiu enquanto fenômeno da vida social, indicando a margem do mundo habitado. "Na medida em que os padrões de civilização foram se desenvolvendo acima do nível de subsistência, as fronteiras entre ecúmenos tornaram-se lugares de comunicação e, por conseguinte, adquiriram um caráter político" (MACHADO, 1998, p. 41)

Diante disso, quando se pensa em áreas de fronteira dificilmente relaciona-se com a ocorrência de agronegócios. Áreas de fronteira no Brasil tem uma ligação muito forte com o desenvolvimento de atividades terciárias, especialmente o comércio, visto que, historicamente tratam-se de áreas onde os processos ligados ao transporte de mercadorias ocorriam pelas bacias hidrográficas, bastante presentes nas fronteiras.

Para Oliveira (2009), a fronteira internacional possui dinâmicas distintas em relação as demais regiões do território nacional. Com o decorrer do tempo e influenciado por objetivos governamentais de delimitação e definição das fronteiras, tais áreas tornaram-se lugares pouco atraentes, especialmente no que diz respeito ao desenvolvimento da agropecuária, embora a atividade tenha sido o cerne da povoação das fronteiras.

Apesar das fronteiras caracterizarem-se fortemente por suas atividades comerciais e de serviços, o agronegócio tem desenvolvido-se em diversas áreas de fronteira. Para abordar essa temática o trabalho apoiou-se em revisão de bibliografia, levantamento de dados, além de pesquisa de campo. $O$ mesmo encontra-se dividido em três partes. Inicialmente será realizada uma discussão sobre o conceito de fronteira, suas características e seu desenvolvimento, posteriormente a abordagem se dará no sentido de verificar o desenvolvimento do agronegócio no município de Uruguaiana/RS e por fim serão traçadas algumas considerações a respeito desse processo. 


\section{Áreas de fronteira: breves considerações}

Historicamente, a fronteira tornou-se objeto constante de preocupação dos Estados em relação ao controle e ao vínculo. Não é estranho que um dos objetivos do sistema histórico de Estados nacionais, em vigor por praticamente dois séculos, foi o de incentivar a coincidência entre limite e fronteira, tendo como resultado uma convergência conceitual que em muitos casos são considerados como sinônimo na literatura (MACHADO, 2009).

Em seu estudo, Ferrari (2012) explicita que o principal debate sobre fronteiras encontra-se no questionamento de Gottman sobre a dúvida em relação à fronteira ser uma linha ou uma zona. Gottman (2007) considera a linha um conceito político e jurídico, enquanto zona seria um conceito geográfico. Ferrari (2012, p.17) aponta que "[...] se a fronteira é uma zona geográfica, sua noção universalmente difundida como linha que separa duas soberanias seria equivocada, pois as linhas não passam de uma abstração sem existência real exceto dentro da cartografia". Raffestin (1993) também apoia-se na ideia de zona, pois argumenta que a fronteira constitui-se em uma zona camuflada em linha, pois cada demarcação linear muito precisa, corresponde a uma zona geográfica.

O termo fronteira deriva do latim, fazendo referência a uma porção do território situado à frente (FERRARI, 2012). Na França, a palavra fronteira (frontéire) surgiu no início do século XIV e a sua utilização ocorreu através dos militares que iam ao front para defender o território real contra possíveis invasores. Para isso eram construídas fortificações militares, que posteriormente passaram a ser chamadas de fronteira. Assim, a expressão abarca duplo sentido, o movimento de conquista e fixação de demarcação e delimitação das zonas conquistadas. A formação dos Estados nacionais no contexto da Europa colaborou para que o termo fronteira fosse reconhecido enquanto limites políticos dos Estados nacionais. Machado (1998, p. 41) argumenta que

A origem histórica da palavra mostra que seu uso não estava associado a nenhum conceito legal e que não era um conceito essencialmente político ou intelectual. Nasceu como um fenômeno da vida social espontânea, indicando a margem do mundo habitado. $\mathrm{Na}$ medida em que os padrões de civilização foram se desenvolvendo acima do nível de subsistência, as fronteiras entre ecúmenos tornaram-se lugares de comunicação e, por conseguinte, adquiriram um caráter político. 
Ao serem criados, os Estados nacionais já receberam um espaço dividido, visto que preexistia aos territórios uma separação espacial do trabalho e uma divisão política do território. "Com o desenvolvimento do capitalismo a divisão do mundo em territórios nacionais se sedimenta, e é com base nesta estrutura que as sociedades politicamente se enquadram" (CATAIA, 2007, p.3). Nesta perspectiva, as fronteiras tem o papel de limites demarcadores de distintos projetos sociopolíticos.

Dorfmann e Rosés (2005) explicitam que, a fronteira é uma característica de qualquer objeto ou fenômeno, cuja existência possua extensão e fim. O fim ou fronteira diz respeito ao contato, caso exista um objeto ou fenômeno de semelhante natureza adjacente ao primeiro. Em relação aos Estados-nação, a fronteira é considerada enquanto fronteira internacional. Desse modo, "Fronteira é o espaço onde se entrelaçam as influências dos estados em contato. Atividades econômicas, sociais e culturais aí se encontram, criando práticas compartilhadas que podem construir uma identidade fronteiriça" (DORFMANN; ROSES, 2005, p.195).

Em relação às delimitações de fronteira em território brasileiro, Machado (2000) explicita que, na segunda metade do século XVIII o perímetro das fortalezas e casas fortes que concentravam-se no decorrer da costa, passou a expandir-se no intuito de anexar as margens das terras do Estado brasileiro. Ainda que a linha de fortificações pombalinas assemelha-se ao atual limite das terras brasileiras, formalizado primeiramente no Tratado de Madri em 1750, ela concretizou-se apenas após a revogação do tratado.

Não obstante ter sido anulado (1761), o Tratado de Madri constitui
uma referência ainda válida para o estudo do processo histórico de
legitimação dos limites das terras brasileiras, tendo em vista as
inovaços introduzidas por quatro anos de negociações diplomáticas.
Entre as inovações destacamos: a) o reconhecimento da superação
da linha de Tordesilhas; b) a primeira tentativa de estabelecer os
limites entre as possessões lusas e castelhanas num sentido
continental; c) uma visão ampla da geopolítica mundial, em que se
estabelece a separação entre os conflitos que pudessem ocorrer na
Europa (entre as potências signatárias) e os conflitos americanos
(Artigo XXI); por fim, d) o deslocamento, na ordem jurídica, do
princípio romano do Direito Civil, denominado de uti possidetis
(consagrado ao direito de propriedade e posse sobre terras) para o
campo do Direito Público (Artigo 1IL) (MACHADO, 2000, p.12).

A autora menciona uma segunda referência adotada no Tratado de Madri, os lugares de povoamento, especialmente as terras dominadas pelas missões jesuíticas. As missões espanholas estendiam-se pelo centro da América do Sul, desde o Paraguai até Maynas, constituindo uma efetiva faixa de fronteira no sentido Norte-Sul; o mesmo papel que tiveram as missões religiosas portuguesas na porção 
oriental da Bacia Amazônica. Essas parcelas foram fundamentais para o traçado de limites e para o cumprimento do uti possidetis. A terceira referência foram os elementos físicos. Não existindo o reconhecimento do direito indígena ao território, considerável parte das terras eram tratadas enquanto áreas vazias. Assim, os limites seguiriam os acidentes físicos, em especial as fronteiras fluviais.

Os limites das possessões até o século XVIII, fossem reinos ou soberanias, eram frequentemente imprecisos. Da mesma forma ocorreu nas colônias sulamericanas, no entanto trata-se de uma perspectiva posterior dos acontecimentos, visto que naquele momento o interesse das Coroas ibéricas pela definição da posse e o traçado de limites, principalmente da Coroa portuguesa em investir na ocupação das fronteiras, possuía intuito concreto e imediato (FERRARI, 2012).

Como consequência da revogação do Tratado de Madri e considerando a incerteza dos caminhos nas guerras no sul com a Espanha, além da situação econômica metropolitana resultante da queda das exportações de ouro brasileiro, o governo priorizou a defesa das fronteiras e o contrabando. A saída para esses entraves seria, na perspectiva portuguesa, a construção de fortificações nas áreas que não constavam no tratado. Desta forma, as fortificações estabelecidas nas principais rotas de comunicação constituíram-se em verdadeiros elementos de fronteira, tendo a tarefa ainda de intensificar os povoamentos. Shaffer (1991) aponta que, as fronteiras terrestres dos países sul-americanos foram marcadas pela dispersão do povoamento, pelos vazios humanos, pela falta de clareza nos traçados, pelos conflitos, pela posse de terra e pela fragilidade dos vínculos entre países vizinhos.

A legislação nacional voltada para as áreas de fronteira é densa, já que são consideradas estratégicas para o país. No final do século XIX a faixa de fronteira foi definida pela primeira vez enquanto área geográfica com regime jurídico particular, pela lei 601 de 1890 (NUNES, 2013). De acordo com esta lei, a utilização e propriedade de terras na extensão da faixa da fronteira estava sujeita a condições distintas das outras partes do território, pois esta faixa de terras estendia-se ao longo dos limites do território nacional e poderia ser concedida gratuitamente. Em 1891 a Constituição estabelecia que todas as terras devolutas localizadas nos respectivos territórios pertenciam ao Estado, competindo a União somente a porção do território que fosse indispensável para defesa das fronteiras, fortificações, construções militares e estradas de ferro federais. 
Nessa discussão é fundamental compreender que "[...] a identificação entre limite e fronteira internacional decorre provavelmente da mobilidade e da imprecisão cartográfica que na maior parte do tempo acompanharam o desenvolvimento das sociedades" (MARTINS, 1997, p.47). A partir daí as demarcações lineares manifestadas através de uma realidade política territorial distinta estaria ligada a noção de fronteira. Desta forma concorda-se com Ferrari (2012, p.19)

Por demarcação linear entende-se a fixação da linha limite com a implantação de marcos sobre o terreno, permitindo identificar o fim ou começo de um domínio político territorial, passando o limite a compreender a linha de controle legal de um Estado-nação, ao passo que a fronteira é tida como zona geográfica entre dois sistemas estatais diferenciados.

O limite político territorial define o campo de atuação que aparelha a atuação do poder para governar, controlar e restringir determinadas ações sociais no espaço definido. Em relação à faixa de fronteira, esta foi sendo ampliada nas Constituições do Brasil. Na constituinte de 1930 a delimitação da faixa passou para $100 \mathrm{Km}$, sendo que nenhuma concessão poderia ser feita no sentido de disponibilizar terras nas áreas das fronteiras para atividades produtivas. Já a concessão de terras na faixa de fronteira a fim de implantação de infraestruturas, poderia ocorrer sem audiência prévia do Conselho Superior de Segurança Nacional (CSSN).

A Constituição de 1934 foi apresentada sem mudanças no que concerne a função da faixa de fronteira (NUNES, 2013). A alteração mais significativa na Constituição foi em 1937 no governo de Getúlio Vargas, com ampliação da extensão para $150 \mathrm{~km}$ de faixa de fronteira. No ano de 1939 foi criada a Comissão Especial de Revisão da Concessão de Terras, a qual tornou-se responsável pela realização de estudos e emissão de pareceres sobre a instalação de empresas e das atividades desenvolvidas, além da implantação de vias de transporte e redes de comunicação.

Para Linhares e Teixeira da Silva (1999), a política de Vargas estava relacionada com questões de urbanização e industrialização. Buscava-se o abastecimento das cidades e o suprimento das demandas de matéria-prima, situação que inclinava a reorientação da agricultura do mercado externo para o interno.

A intervenção estatal buscava, entre outros fatores, incentivar a mobilidade da fronteira econômica com o objetivo de incorporar amplos espaços vazios do país ao processo produtivo; reunir diversos núcleos demográficos isolados, povoando racionalmente 0 país, assumindo uma ideologia da fronteira ou do bandeirantismo, aspecto central nas estratégias governamentais (BESKOW, 2007, p.2). 
É no decorrer do Estado Novo (1937-1945) que as ideias de integração nacional são reunidas a fim de compor o projeto Marcha para Oeste. O projeto tinha por objetivo a ocupação dos espaços vazios do oeste, visando a disseminação da pequena propriedade através da destinação de terras públicas. Silva (1997) explica que essas áreas não encontravam-se totalmente vazias, pois estavam ocupadas por usinas de açúcar, plantações de erva-mate, fazendas de gado, áreas de garimpo, entre outros. Para a autora, isto reforça a ideia de que a ocupação de terras devolutas continuava a ocorrer, apesar dos inúmeros decretos que proibiam a usucapião nas terras públicas.

Com o início do governo militar em 1964, nota-se o aprofundamento de uma política estatal com vistas a novas estratégias no sentido de preservar a fronteira nacional. Embora tais estratégias para defesa das fronteiras não fossem divulgadas publicamente, ganharam visibilidade com as propostas que passaram a ser conhecidas como geopolíticas, com destaque para aquelas defendidas por Golbery de Couto e Silva (1981).

Se o século XIX foi marcado pela consolidação do Estado-nação e pela definição de fronteiras, fundamentais para a expansão capitalista, o período pósSegunda Guerra Mundial caracterizou-se pelos movimentos de adesão de países sob a forma de comunidades econômicas. Mantidas as fronteiras, elegem-se medidas tarifárias de integração. Assim, desde então a integração foi concebida como articulação econômica, como cooperação comercial entre nações com determinada proximidade espacial e com certa afinidade política (SHAFFER, 1991).

Em relação à integração enquanto caminho para o crescimento, a integração fronteiriça é considerada uma variante que merece atenção no sentido de que, as desigualdades entre economias nacionais próximas, com atração de recursos, especialmente humanos, de um país em relação a outro, pode transformar-se em uma situação não esperada da integração em âmbito local. Nesta discussão Oliveira (2009) explicita que, o espectro conjuntural que está presente e que atinge todos os lugares na fronteira é mais intenso e imediato, tendo constantes mudanças nas oscilações políticas e na economia de cada país

Todas as vezes que muda a correlação cambial (geralmente entre a moeda local e o dólar americano), significativamente muda também o sentido dos fluxos de trocas mercantis na fronteira; qualquer mudança na postura política de governos em relação ao estado vizinho, imediatamente, na fronteira, se ordena manifestações em função desta postura. Ou seja, essa lógica possui, como princípio, a 
oscilação e a condição pendular dos investimentos (OLIVEIRA, 2009, p. 22).

As proporções são maiores quando essa situação desencadeia na fronteira processos atrativos de inserção industrial e novas ofertas de serviços e comércio. No caso da inserção industrial, que muitas vezes é atraída por vantagens comparativas como o comércio de reexportação, afeta o cotidiano e a produção das fronteiras. Além disso, interferem as formas ilícitas do narcotráfico e demais formas de contrabando.

A fronteira internacional possui dinâmicas distintas em relação às demais regiões do território nacional. São áreas onde os indivíduos trocam bens e produtos que em muitos casos são diferenciados daquelas realizadas pela soberania de seu Estado (OLIVEIRA, 2009). Em relação às fronteiras sul-americanas, Oliveira et al (2004) apontam que, a condição multiforme do território fronteiriço faz com que as organizações econômicas elaborem modelos próprios de troca, cada vez mais porosos na circulação de serviços, bens e pessoas. Por um lado as organizações econômicas conduzem a população a vivenciar diversas interações, o que gera e intensifica as relações horizontais. Por outro lado, as mesmas condições permitem que as organizações políticas sigam no mesmo caminho, contudo sem ideia de interação.

A partir dessa breve discussão sobre o conceito de fronteira, sua legislação e principais características, a seguir será abordada uma temática importante, embora pouco discutida, acerca do desenvolvimento do agronegócio em áreas de fronteira, neste caso específico, trata-se do agronegócio no município fronteiriço de Uruguaiana.

\section{Agronegócio em áreas de fronteira: o caso de Uruguaiana}

Ao iniciar a discussão sobre o agronegócio, é necessário lembrar que, a crise da economia mundial, a partir da década de 1970, estimulou a necessidade de uma reestruturação técnico produtiva.

Essa reestruturação visa a redução do uso de tecnologias vinculadas as formas de produção baseada no modelo fordista. As alterações passam pela incorporação de novas tecnologias de produção e produto e novos métodos organizativos. A modificação no padrão técnico-produtivo-organizacional, tornou-se possível através da introdução de novas tecnologias com base na microeletrônica, que manifesta-se na robótica, na automação integrada por computadores, nas técnicas de desenho e engenharia. Essas novas tecnologias 
substituem à produção rígida pela forma de produzir mais flexível (ESPÍNDOLA, 2015, p.2).

A expansão dos agronegócios brasileiros nos últimos cinquenta anos provocou grandes alterações na estrutura de mercado e na introdução da agropecuária no complexo produtivo da agricultura. A análise produtivista desse processo leva ao erro de considerá-lo apenas sob a ótica da relação mais próxima entre agricultura e indústria, com a crescente intersecção produtiva implantada pelo processo de industrialização advinda da Segunda Revolução Industrial. "Em economias continentais como a brasileira, exigente em irradiar esse processo por largo espaço territorial, essa transformação conforma-se como um autêntico processo de agroindustrialização" (GONÇALVEZ, 2005, p.7).

A agropecuária se estabelece enquanto um elo da produção de riqueza, multiplicada por setores emancipados do antigo complexo rural, para constituir estratégicos setores da agroindústria de insumos e máquinas, das agroindústrias processadoras e das agroindústrias de alimentos e vestuários.

Gonçalvez (2005) evidência que, a sobrevivência do agropecuarista o induz a trabalhar com um único produto, anulando sua autosuficiência e distanciando o agente produtivo do consumidor. O elemento mais profundo desta mudança e que torna o agropecuarista capitalista, encontra-se no fato de que, sua ação produtiva exige, além da terra e do trabalho, o dinheiro para a compra de maquinário, dos insumos e do trabalho dos empregados, portanto, o crédito torna-se fator indispensável. A agropecuária moderna pode ser realizada com menos terra e menos trabalho, entretanto com muito mais capital, inserindo-se na lógica da expansão da reprodução ampliada do capital, ou seja, a "[...] lógica de reprodução ampliada do capital é lastreada na ação tipicamente capitalista de aplicar dinheiro (D) na produção de mercadorias (M) para obter mais dinheiro (D')" (GONÇALVES, 2005, p. 8).

Diante disso, o complexo de agronegócios da agricultura pode ser considerado uma estrutura de segmentos setoriais, onde a produção biológica passa a ser caminho estratégico para a combinação de insumos e instrumentos criados fora do campo e a ser fornecedora de bens intermediários para estruturas de agregação de valor, envolvendo empreendimentos em cadeias que, tem início nas indústrias de insumos e maquinaria e se finalizam nas estruturas de varejo.

Neste contexto, verifica-se o aumento das formas de venda antecipada de safras, de operações lastreadas em instituições de administração de risco, como as 
Bolsas de Mercadorias e de outros mecanismos de contratualização, que representam um caminho no sentido de gerenciamento da disparidade de poder de mercado, interna as cadeias de produção dos agronegócios.

\begin{abstract}
Mais ainda, porque os ajustes acabam se produzindo no campo, onde se localiza o elo tomador de preços. Isso porque a grande empresa da agroindústria de processamento enfrenta a solidificação de duas estruturas empresariais de mesma ou ainda maior magnitude de concentração do capital, que são os oligopsônios representados pelas 'trading companies' atuantes no comércio exterior - que também atuam comprando diretamente dos agropecuaristas para produtos não processados - e pelas grandes redes de supermercados. Dado que ambos oligopsônios têm imenso poder de mercado e conseqüentemente de formar preços, na execução de sua governança sobre o processo, quando submetidos a pressões que comprometam suas margens, adotam estratégias de repassar o ajuste para os elos à montante das cadeias de produção (GONÇALVEZ, 2005, p.12).
\end{abstract}

Para o autor, esta situação pode comprometer a competitividade setorial. Deste modo, a criação e fortalecimento dos mecanismos de gerenciamento de riscos, na perspectiva institucional, tal como as operações em bolsas de mercadorias, como as câmaras setoriais e os contratos bilaterais, constituem caminho alternativo.

Neste conjunto observa-se a ampliação dos serviços para agropecuária, de preparação e logística, que representam a incorporação de utilidades de beneficiamento, transporte, acesso e armazenagem do produto agrícola. Além disso, ocorre o crescimento e o desenvolvimento dos serviços associados às cadeias de produção da agricultura, a exemplo da assistência técnica e manutenção especializada de equipamentos rurais, agroindústriais, laboratoriais e de informática.

Atrelado a exigência de profissionalização gerencial dos estabelecimentos, ocorre o avanço dos serviços de assistência técnica especializada em planejamento e gestão de empreendimentos, de tributação e contabilidade e de gestão financeira. Os serviços agropecuários transacionais e de distribuição também tem evoluído; nestes serviços estão incluidas as estruturas de intermediação, representadas pelos compradores, pela estrutura do comércio atacadista e pelos equipamentos varejistas na distribuição final. Estas são representadas pelas transações em cadeia, que encaminham os produtos da propriedade ao mercado, abrangendo a organização transacional do fluxo produção/consumo, onde destaca-se o poder de mercado das redes de supermercados na definição de critérios da constituição de preços. 
Atua da mesma forma as trading companies, ou seja, as grandes empresas exportadoras, que destacam-se pela grande capacidade financeira e de gerenciamento de risco. Nesta perspectiva, Frederico (2011) destaca os serviços agropecuários de assessoria, as transações pela exigência de serviços profissionais de elevado conhecimento e de alta credibilidade. Trata-se das corretoras especializadas, essenciais no novo modelo do capital financeiro e que atuam como facilitadoras de negócios nos muitos mercados da agropecuária.

As assessorias de comércio exterior (exportação e importação), os lobistas e grupos de pressão, atuam nos espaços de tomada de decisões estratégicas, a exemplo das políticas públicas. E por fim, os serviços financeiros da agropecuária, através das corretoras, que negociam nas bolsas de mercadorias, bem como nas empresas de gestão financeira e de acompanhamento de agromercados.

\begin{abstract}
Essa maior interdependência, desde logo, implicou numa radical mudança no perfil do Estado Nacional. Na visão vigente, na construção desse processo tinha-se a prevalência do Estado Desenvolvimentista que atuava não apenas como produtor direto, em especial na eliminação dos constrangimentos básicos representados por insumos, energia e transportes, mas também no financiamento do desenvolvimento com base em fundos públicos normalmente aplicados a taxas favorecidas. Esse padrão de intervenção estatal está sendo substituído pela ação do Estado da Regulação, onde as ações governamentais de política institucional não apenas estabelecem normas e procedimentos que regem os parâmetros da atividade econômica como, principalmente, estruturam 0 desenvolvimento de mecanismos de mobilização de recursos para financiamento da produção com base no mercado financeiro (GONÇALVEZ, 2005, p.19).
\end{abstract}

Diante disso Fresca (2016) mostra que, a financeirização teve início na década de 1960 a partir da oferta de crédito subsidiado pelo Estado. A partir da década de 1980 ocorreu o esgotamento dessa forma de financiamento, haja vista as políticas macroeconômicas do período, passando então para inserção da agricultura na lógica do sistema financeiro, primeiramente para a obtenção de crédito barato e depois para demais movimentações financeiras. Surgiram outros meios de venda antecipada e crescimento de mercado futuro, inserindo esses na lógica do desenvolvimento capitalista de forma estável e consistente (FRESCA, 2016).

É neste processo iniciado na década de 1980 que, parte da agropecuária tem obtido financiamento para suas atividades, tal como custeio, capital de giro das agroindústrias e parcela de investimentos. Destaque para o crédito rural, que desde 2003 destaca-se pela grande expansão, totalizando $\mathrm{R} \$ 3.158$ bilhões em 2003 e 
$\mathrm{R} \$ 16.359$ bilhões em 2012. Dentre os programas de financiamento rural consta o sistema financeiro através da Cédula do Produto Rural-CPR, da Letra de Crédito do Agronegócio-LCA e do Certificado de Direitos Creditórios do Agronegócio-CDCA.

As bolsas de mercadorias, por sua vez, surgiram no século XIX e assumiram um papel estratégico no mercado, tal qual as instituições bancárias no processo de financeirização da riqueza. A partir da década de 1980 foram criados novos mecanismos de financiamento da produção para o mercado, lastreados diretamente entre compradores e fornecedores da agropecuária. Já na metade da década de 1990, destaque para as formas de venda antecipada e o crescimento do mercado futuro. Para Gonçalvez (2005), tratam-se das opções mais estáveis para o desenvolvimento capitalista e para a sustentabilidade estrutural, pois as operações no mercado financeiro por meio da inserção de títulos na Bolsa de Mercadorias operam não somente enquanto gestão de risco, mas enquanto parâmetro para vários contratos de venda antecipada. O financiamento da produção, ligado a redução de risco de preços, gera uma estabilidade para a durabilidade de investimentos em inovação.

Em 2012 a carne bovina participou com U\$ 5,9 bilhões das exportações totais do agronegócio (ESPÍNDOLA, 2013). O autor aponta que, o desempenho exportador dessa cadeia produtiva está relacionado a outros elementos, com destaque para o melhoramento genético ${ }^{2}$, a melhoria das pastagens, manejo, sanidade e confinamentos, ao processo de inovação em cortes especiais, a crise da aftosa e da vaca louca na Europa e nos Estados Unidos, aos focos de gripe aviária na Ásia, a redução de oferta mundial de frango por parte da China e dos Estados Unidos, a estabilização da União Européia no mercado mundial, a conquista de novos mercados e a consolidação em mercados tradicionais (Estados Unidos e Europa). Os motivos para o crescimento da produção brasileira de gêneros alimentícios, especialmente os direcionados ao mercado externo, estão relacionados aos seguintes fatores

(1) do crescimento populacional estimado em 7,8 milhões de pessoas em 2.025; (2) do crescimento do processo de urbanização (projeções da ONU, indicam que, em 2025, 61\% da população mundial concentrar-se-á na urbe); (3) da recuperação da economia

\footnotetext{
${ }^{2} \mathrm{O}$ desenvolvimento tecnológico nas agroindústrias de carnes, depende do melhoramento genético dos animais, que por sua vez, utiliza-se de duas ferramentas. A primeira diz respeito a seleção dos animais de uma geração que serão pais da geração seguinte e a segunda trata-se do cruzamento de indivíduos pertencentes a raças ou espécies diferentes (ESPÍNDOLA, 2012). Sobre as técnicas utilizadas, destaque para a Inseminação Artificial e Transferência de Embriões, a micromanipulação e produção in vitro de embriões.
} 
americana; (4) da continuidade do programa de biocombustível dos EUA; e (5) da continuidade da mudança do padrão de consumo mundial (produtos processados, porcionados, orgânicos, entre outros).

Para compreender a dinâmica do agronegócio em Uruguaiana, uma área de fronteira, é preciso considerar que, a ocupação do Rio Grande do Sul teve início no contexto das disputa entre as Coroas da Espanha e de Portugal. Datam do início do século XVII as primeiras incursões jesuíticas ao território gaúcho, que era povoado predominantemente por indígenas. A ocupação da porção sul do estado, onde se encontra Uruguaiana, de acordo com o mapa a seguir, também foi realizada pelos padres da Companhia de Jesus.

MAPA 1: Localização de Uruguaiana/RS

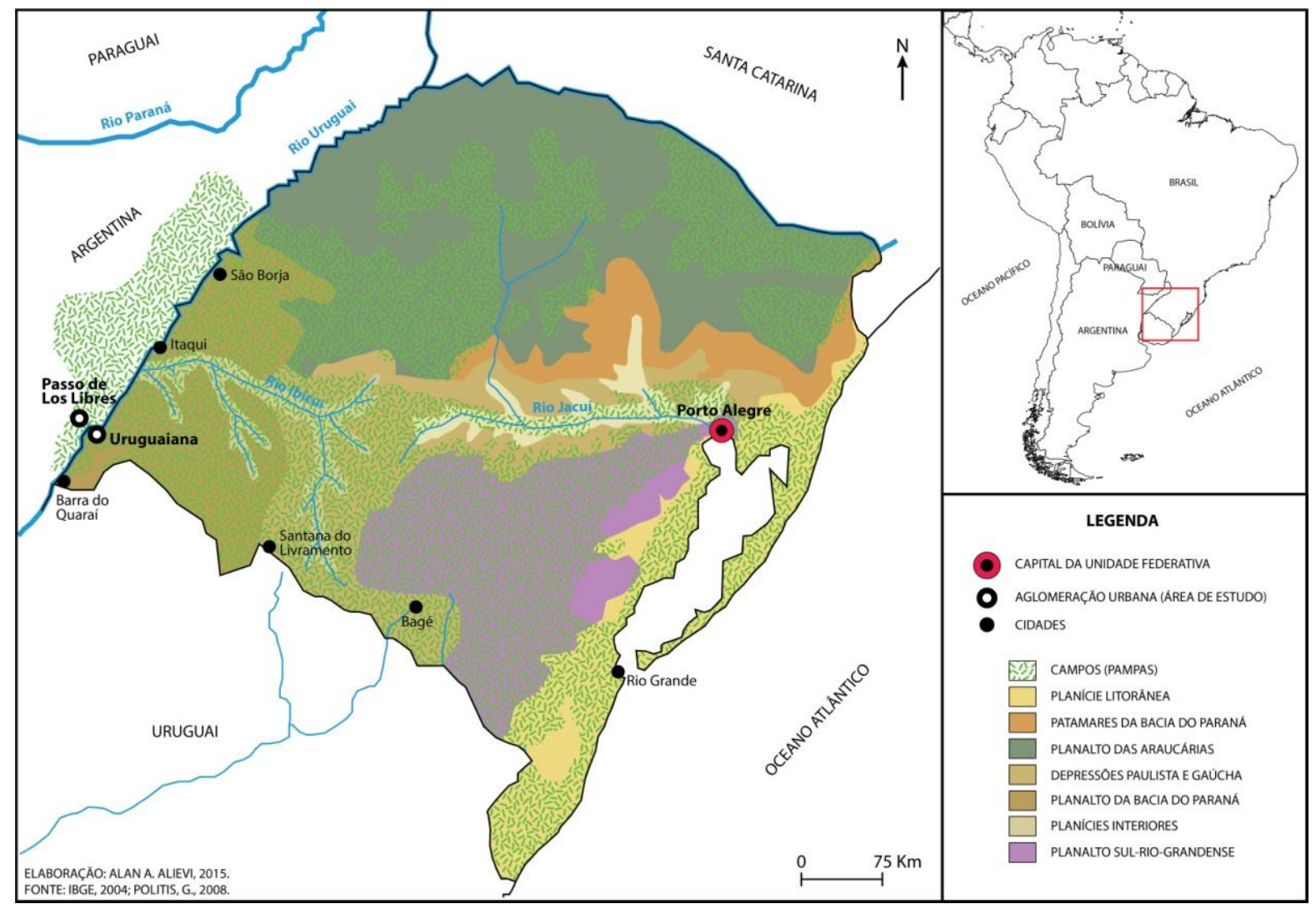

É a partir da doação de sesmarias que se dá a formação das estâncias e da economia baseada na atividade pastoril. Através das doações, verificou-se a oficialização da grande propriedade rural, que marca a constituição da base fundiária da fronteira oeste gaúcha. Já nos primeiros anos de sua criação, a vila exportava mercadorias que representavam valores importantes no total das exportações da província, sendo compostas, em sua maioria, por couro e charque. Sobre as charqueadas, Vieira e Rangel (1993) apontam que, em 1835 existiam 35 charqueadas no estado do Rio Grande do Sul, com abate de cerca de 600.000 
cabeças. As charqueadas fundadas no estado concentravam-se em sua maioria nos municípios da fronteira, sendo Bagé considerado o polo charqueador gaúcho. A interiorização das charqueadas estava ligada com a livre navegação dos rios, a implantação das ferrovias a partir de 1887, bem como pela importância que a fronteira adquiriu no circuito comercial platino.

Aqui vale frisar que, neste período a dinâmica econômica nacional foi dada a partir da expansão da cafeicultura, da chegada de imigrantes, da fundação de cidades, da construção de ferrovias, etc., nos estados do sudeste e sul do país. Destaque para a continuidade da produção açucareira no Nordeste, bem como de economias regionais no extremo sul do Rio Grande do Sul, Mato Grosso do Sul, dentre outros.

Foi, sobretudo, a cafeicultura, a atividade econômica mais representativa, centrada até o início do século XX nos latifúndios através da mão de obra assalariada dos imigrantes, o colonato ${ }^{3}$. Os ramos que mais se desenvolveram até as primeiras décadas do século $X X$ no Brasil foram os de alimentos, têxtil $e$ vestuário. Os segmentos de tecidos de algodão, lã e juta, produção de açúcar, fósforo e cerveja, já estavam consolidados como industriais, enquanto outros mantinham características manufatureiras e artesanais, como as produções de chapéus, calçados, cigarros e charutos, móveis, banha, charque, assim como os curtumes e oficinas mecânicas e fundições.

Além do crescimento da indústria têxtil, o setor de alimentação teve importante destaque no início do século $X X$, apesar de alguns segmentos continuarem com características manufatureiras, tal qual os estabelecimentos produtores de banha de porco e as charqueadas, especialmente no Rio Grande do Sul. Com incentivos governamentais foram criados frigoríficos em São Paulo, que posteriormente passaram a ser controlados por capitais norte-americanos e ingleses. Além da carne, ocorreram avanços nas usinas de açucar no Nordeste e no Rio de Janeiro 4 .

\footnotetext{
3 No processo de substituição do trabalho escravo ocorreu a contratação de trabalhadores, majoritariamente de origem européia, em unidades familiares para o trabalho no café. Ao contratar os serviços do colono, o fazendeiro estava contratando o trabalho de toda familia. O colonato combinava um pagamento fixo em dinheiro, uma quantia proporcional ao volume de café colhido, além da possibilidade de plantar e criar para a própria família (SILVA, 2007) .

${ }^{4}$ No final do século XIX a cidade do Rio de Janeiro ocupava o primeiro lugar, não apenas no setor têxtil, mas em geral. Em 1907 contribuiu com 33,1\% da produção brasileira, quando todo o estado de São Paulo participou com 16,5\%. Todavia, durante a primeira guerra mundial, São Paulo assumiu a liderança, ampliando significamente com o tempo (MAMIGONIAN, 2000).
} 
Além das vantagens legais da localização fronteiriça, o contrabando teve papel importante no crescimento das charqueadas, principalmente no que se refere aos transportes ilícitos, práticas constantes naquela área. De acordo com Soares (2006), o transporte de gado em pé era facilitado pela existência de um considerável número de proprietários gaúchos que possuíam estâncias no Uruguai. Soma-se a isso a instalação dos frigoríficos nas primeiras décadas do século $\mathrm{XX}$, elemento responsável por transformações nas áreas pecuárias.

Aspecto fundamental para a economia de Uruguaiana diz respeito a introdução da rizicultura em suas terras. O ano de 1943 é marco neste processo, visto que o Instituto Riograndense do $\operatorname{Arroz}^{5}$ (IRGA) comprou a primeira fração de terras no município para a instalação de uma colônia de produtores de arroz (colônia rizícola ํㅡㄹ 2), com o objetivo de difundir o plantio do cereal no estado. Entre 1944 e 1947, o município já cultivava mais de 3.500 hectares de arroz e uma média de 10.000 toneladas.

O rebanho bovino, por sua vez, contava, em 1940, com 340.080 cabeças, seguido do rebanho equino, com 27.153. Contudo, o maior destaque neste momento são os ovinos, com 575.571 cabeças recenseadas. O considerável rebanho ovino estava relacionado com a demanda de lã, que teve crescimento a partir da Primeira Guerra Mundial.

Chelotti e Bezzi (2011) apontam que, a Segunda Guerra Mundial favoreceu também, o fortalecimento da rizicultura nacional. Neste sentido, a combinação de fatores como o crescimento do mercado interno e a crescente urbanização, associada as condições de mercados externos importadores de alimentos em função da Guerra, foram os responsáveis pelo crescimento da produção de arroz no Rio Grande do Sul e especialmente em Uruguaiana.

Verifica-se então, a consolidação de uma agricultura voltada para o mercado interno que crescia em função de um mercado externo que necessitava uma grande demanda de gêneros alimentícios, onde este momento vivido pelo espaço agrário gaúcho é de suma importância, pois o Rio Grande do Sul tornava-se abastecedor de grande parcela de gêneros alimentícios, especialmente o arroz. A evolução favorável das exportações de produtos agropecuários e agroindustrializados do Rio Grande do Sul destinados ao mercado interno estava estreitamente associada ao notável desempenho da economia agroexportadora na década de vinte e a retomada do

\footnotetext{
${ }^{5}$ O IRGA teve início a partir do Sindicato Arrozeiro do Rio Grande do Sul, que transformou o sindicato no Instituto do Arroz do Rio Grande em 1930. Seu principal objetivo era a defesa dos segmentos da rizicultura, o desenvolvimento de pesquisa e assistências técnicas aos produtores. Em 1940 o IRGA tornou-se entidade pública com a finalidade de incentivar, coordenar e superintender a defesa da produção, da indústria e do comércio do arroz produzido no estado. Disponível em: http://www.irga.rs.gov.br/
} 
crescimento industrial na década de trinta, sustentada em altas taxas de expansão dos produtos agrícolas. Este processo foi responsável pela expansão do mercado nacional consumidor de alimentos, aprofundando assim a divisão nacional do trabalho (CHELOTTI, BEZZI, 2001, p.54).

Após a segunda metade do século $X X$, especialmente a partir da década de 1960 e intensamente na década de 1970, verifica-se o avanço na introdução de novas técnicas nas atividades agropecuárias gaúchas. Isso se deu principalmente pela política de crédito subsidiado, e em Uruguaiana foi importante porque ocorreu no momento em que se dava a introdução e a expansão da rizicultura.

O arroz teve crescimento de 58,9\% entre 1980 e 2006, quando registrou 590.329 toneladas colhidas de 71.124 hectares. A área utilizada aumentou 15.352 hectares nesse mesmo período. A safra de 2015/2016, por sua vez, rendeu 695.044 toneladas de uma área de 83.030 hectares (IRGA, 2016). Neste sentido, um elemento importante para compreender a estrutura fundiária do município, diz respeito a dimensão das propriedades produtoras de arroz. Segundo o Irga (2016), na safra de 2015/2016, dos 258 estabelecimentos que cultivaram arroz, 150 possuiam área superior a 200 hectares.

Brum e Bezzi (2009) apontam que, a rizicultura desenvolvida no Rio Grande do Sul foi incentivada por políticas governamentais e deste modo, a expansão da atividade esteve alicerçada no incentivo de órgãos como o Incra, a Emater e a Embrapa, bem como do governo do estado por meio das Secretarias Municipais de Agricultura. $\mathrm{O}$ acesso a políticas de crédito e financiamento foi um dos elementos principais da expansão da agricultura em áreas tradicionais da pecuária. As lavouras de arroz são cultivadas majoritariamente nas grandes propriedades, contudo, ocorre considerável número de arrendamentos. O IRGA (2016) aponta que, dos 550 produtores de arroz de Uruguaiana, 340 são arrendatários. $O$ arrendamento na produção de arroz é geralmente acordado em número de sacas de $a r r o z^{6}$, podendo o acerto ser feito em seu valor ou sobre sua produtividade. Existe também o arrendamento de água, sendo este um dos principais fatores no custo da produção do arroz irrigado ${ }^{7}$.

Em relação ao beneficiamento, Portela (2007) evidência que, os municípios que mais industrializam o arroz na região da Campanha são Itaqui e São Borja. Estão instalados em Uruguaiana os escritórios das principais marcas, como a Camil,

\footnotetext{
${ }^{6} \mathrm{Em} 2016$ o valor do saco de 50 quilos de arroz é de $\mathrm{R} \$ 40,00$ (IRGA, 2016).

7 De acordo com o presidente da Associação dos Arrozeiros de Uruguaiana, grande parte dos produtores de arroz possuem açudes em seus estabelecimentos para a irrigação do arroz.
} 
Josepar, Tio João, Ceolin, Prato fino, Namorado, Zaeli e Pilleco. De acordo com o presidente da Associação dos Arrozeiros (2016), todo o arroz produzido em Uruguaiana sai do município em casca e é beneficiado em outros locais.

Além disso, na Campanha gaúcha estão presentes quatro cooperativas de arroz, cuja participação destas na produção é de $15,06 \%$ do total colhido na região, com destaque para a Cooperativa Agroindustrial Alegrete, com participação de 7,5\% no total regional. "Atualmente as cooperativas conservam apenas a atividade de recolhimento do arroz junto aos produtores associados, assumindo um papel de armazenadoras e repassadoras do produto para as demais companhias" (PORTELA, 2007, p.11).

Importante destacar a presença da Bolsa de Mercadorias em Uruguaiana. Trata-se de uma plataforma eletrônica de comercialização de produtos agrícolas para ofertas públicas de arroz. Em Uruguaiana isso ocorre diretamente com produtores rurais, cooperativas, cerealistas e outros interessados, com objetivo de fomentar negócios com arroz em casca através de leilões de produções anuais ${ }^{8}$ (MARQUES et al, 2006). Esta comercialização pode ser realizada após o credenciamento de uma corretora da Bolsa Brasileira de Mercadorias.

Em entrevista realizada com o presidente da Associação dos Arrozeiros de Uruguaiana (2016), a comercialização do arroz através dos leilões da Bolsa de Mercadorias não tem muito destaque, fazendo com que as poucas transações comerciais entre produtores de Uruguaiana e a bolsa, ocorram por meio da Bolsa de Mercadorias de Porto Alegre. A justificativa é de que, tratam-se de produtores que tradicionalmente vendem seus produtos direto para as indústrias e que não adequaram-se ao processo de venda através da bolsa. No entanto, deve-se considerar que este é um serviço relativamente novo do ponto de vista de opção de venda do arroz e por isso, possivelmente existam mais produtores utilizando a Bolsa de Mercadorias para efetuar a venda das produções, mas sem conhecimento da Associação dos Arrozeiros de Uruguaiana, visto que parte dos produtores do município não participam da mesma. Neste contexto é importante apontar que, o PIB de Uruguaiana em 2014 foi de $R \$ 2.295 .349$, onde $24 \%$ veio do arroz.

Um elemento fundamental no processo de produção do arroz diz respeito as relações sociais, que em Uruguaiana ocorrem por assalariamento e por contratação

\footnotetext{
${ }^{8}$ Entre os objetivos da Bolsa de Mercadorias, estão: "[...] desenvolver e prover o funcionamento de sistemas para negociação de mercadorias, bens, serviços e títulos, nas modalidades a vista, a prazo e a termo, viabilizando a formação de grande mercado nacional para commodities agropecuárias, com mecanismos modernos de formação de preços e sistema organizado de comercialização" (MARQUES et al, 2006, p.38).
} 
temporária. De acordo com o IRGA (2009), para cada 30 hectares cultivados, um posto de trabalho é criado 9 . O presidente da Associação dos Arrozeiros (2016), em entrevista, salienta que, a maior parte dos estabelecimentos contrata pessoal para trabalho temporário no período das safras, contudo, os mesmos mantem alguns trabalhadores e suas famílias no próprio estabelecimento, e além do salário, recebem moradia e participação na produção ${ }^{10}$.

A pecuária, assim como a rizicultura, é uma atividade importante para o município de Uruguaiana. Os rebanhos mais importantes são bovinos e ovinos, sendo que a criação de ovinos apresentou diminuição significativa, passando de mais de um milhão de cabeças em 1980, para 170.159 em 2006. Em relação ao rebanho bovino, em 2006, totalizava 557 estabelecimentos e 368.646 cabeças. Maior parte deste rebanho é comprado pela JBS. A partir do melhoramento genético teve um importante crescimento, que soma-se a venda de sêmens e do gado das cabañas, que ocorre por meio de leilões nacionais e internacionais. O gado criado em Uruguaiana é destinado ao corte, entretanto, o abate e o processamento da carne não são realizados no município, visto que o mesmo conta com apenas um frigorífico, que atende a demanda local.

\section{Considerações Finais}

A dinâmica que ocorre em áreas de fronteira está, historicamente, relacionada com atividades terciárias. Isso ocorre pela facilidade de acesso aos países com os quais os municípios brasileiros fazem fronteira, bem como pelas alterações cambiais que, periodicamente ocorrem, ora beneficiando um munícipio, ora outro, Além, é claro, do processo histórico de demarcação territorial com a definição da faixa de fronteira e as atividades que podem ser desenvolvidas nas mesmas.

O processo de delimitação e definição das fronteiras, como o projeto Marcha para Oeste, desenvolvido pelo governo brasileiro na década de 1940, imprimiu nas áreas de fronteira uma imagem de lugares de contrabando e fuga (MACHADO, 2000), ou seja, lugares onde o desenvolvimento industrial e a agropecuária e seus agronegócios não desenvolvem-se. Apesar disso verifica-se que, a agropecuária tem se mostrado importante atividade para diversos municípios fronteiriços, a

\footnotetext{
${ }^{9}$ Em 2006, de acordo com o Censo Agropecuário, eram 3.757 empregados permanentes e 489 temporários.

$10 \mathrm{O}$ salário dos trabalhadores fixos (que residem nos estabelecimentos) é de aproximadamente $\mathrm{R} \$$ $1.800,00$. Além do salário, recebem toda a infraestrutura, e alguns também possuem a participação na produção, que segundo o presidente da Associação dos Arrozeiros (2016), pode chegar a 400 sacas de arroz por safra.
} 
exemplo da rizicultura e da pecuária em Uruguaiana, que encontram nos agronegócios as principais atividades econômicas do município.

Neste sentido verificou-se que, a partir da formação socioespacial com base na grande propriedade, a pecuária esteve presente no município desde sua gênese, com período de destaque com as charquedas e seguimento através da pecuária de corte e melhoramento genético. É, contudo, a partir da inserção da rizicultura, apoiada na modernização da agricultura, que o agronegócio despontou e, juntamente com a pecuária, tornaram-se atividades fundamentais no desenvolvimento do agronegócio do município.

\section{REFERÊNCIAS}

BESKOW, G, C. Marchando para Oeste - Discursos sobre as políticas Varguistas de Integração Nacional. XXIV Simpósio Nacional de História, Anais... São Leopoldo, 2007.

BRUM, N; BEZZI, M, L. Regiões Culturais: a construção de identidades culturais no Rio Grande do Sul e sua manifestação na paisagem gaúcha. Sociedade e Natureza, n.2, Uberlândia, 2008.

CATAIA, M. A relevância das fronteiras no período atual: unificação técnica e compartimentação política dos territórios. Scripta Nova, v. XI, n.245, Barcelona, 2007.

CHELOTTI, M, C; BEZZI, M, L. Perspectivas da cadeia produtiva do arroz irrigado no sudoeste do Rio Grande do Sul. Disponível em:

http://observatoriogeograficoamericalatina.org . Acesso em 14 de janeiro de 2018.

DORFMAN, A; ROSES, G, T, B. Regionalismo fronteiriço e o acordo para os nacionais fronteiriços Brasileiros Uruguaios. In: OLIVEIRA, T, C, M de (org.). Campo Grande: Ed. UFMS, 2005.

ESPÍNDOLA, C, J. Notas sobre as recentes exportações brasileiras de commodities agropecuárias. Revista Princípios, n. 125, São Paulo, 2013.

Brasil. Disponível em:

,C, J. Reestruturação Técnico-produtiva na cadeia de frango do Sul do

http://observatoriogeograficoamericalatina.org.mx/egal8/Geografiasocioeconomica/Geografia economica/17.pdf . Acesso em 23 de junho de 2018.

FERRARI, M. As noções de fronteira em Geografia. Perspectiva Geográfica, v.9, n.10, Marechal Candido Rondon, 2012.

FREDERICO, S. As cidades do agronegócio na fronteira agrícola moderna brasileira.

Caderno Prudentino de Geografia, n.33, v.1, Presidente Prudente, 2011.

FRESCA, T, M. Rede urbana, rede bancária e aspectos da topologia do sistema

financeiro. Seminário Internacional de Geografia e Finanças. Universidade de São Paulo, São Paulo, abr, 2016. 
GONÇALVEZ, J, S. Agricultura sob a égide do capital financeiro: passo rumo ao aprofundamento do desenvolvimento dos agronegócios. Informações Econômicas, v.35, n.4, São Paulo, 2005.

GOTTMAN, J. A urbanização e a paisagem americana: o conceito de megalópole. In: COHEN, S. B. (Org.). Geografia humana nos Estados Unidos, Rio de Janeiro: Fórum, 1970.

LINHARES, M, Y; TEIXEIRA DA SILVA, F. Terra Prometida. Rio de Janeiro: Editora Campus, 1999.

MACHADO, L, O. Limites, Fronteiras, Redes. In: STROHAECKER, T, et al. (Org.).

Fronteiras e Espaço Global. Porto Alegre: AGB-Seção Porto Alegre, 1998.

, L, O. Limites e fronteiras: da alta diplomacia aos circuitos da ilegalidade.

Revista Território, ano V, n.8, Rio de Janeiro, jan/jun, 2000.

MAMIGONIAN, A. Teorias sobre a industrialização brasileira. Cadernos geográficos, n. 2, p. 7, Florianópolis, 2000.

MARTINS, A, R. Fronteiras e Nações. São Paulo: Contexto, 1997.

MARQUES, P.V; MELLO, P. C de; MARTINES, J, G. Mercados Futuros e de Opções Agropecuárias. Série Didática no D-129, Departamento de Economia, Administração e Sociologia da Esalq/USP, Piracicaba, 2006.

NUNES, M. A. Contrastes e convergências socioterritoriais na faixa de fronteira internacional oeste brasileira: impactos das políticas contemporâneas. Tese (Doutorado em Geografia) 2013, Universidade Estadual Paulista, Rio Claro, 2013.

OLIVEIRA, T. C. M. "Os elos de integração: O exemplo da fronteira Brasil-Bolívia". In: COSTA, E. A \& OLIVEIRA, M. A. M (Org.). Seminário de Estudos Fronteiriços. Corumbá: UFMS, 2009.

.T, C, M de; HIGA, T, C, C, S de; PAIXÃO, R, O; MOURA, R; CARDOSO, N, A.

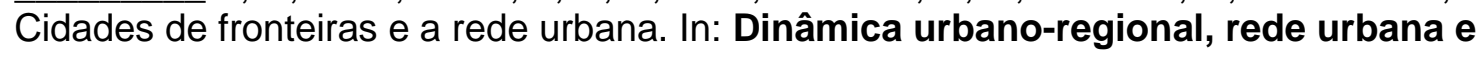
interfaces. PEREIRA, R, H, M; FURTADO, B, A (org.). Brasília: IPEA, 2004.

PORTELA, E, F, M. As estratégias de competitividade para a cadeia produtiva do arroz: o caso das cooperativas da Fronteira Oeste do Rio Grande do Sul (Brasil). Revista

Desenvolvimento em Questão, v.5, n.9, jan./jun. 2007.

RAFFESTIN, C. Por uma Geografia do Poder. São Paulo: Ática, 1993.

SCHAFFER, N. Pesquisa do Rio Grande do Sul. Morador e moradia em periferia e cidade de fronteira: Condições socio-económicas em vilas de Santa Ana do Livramento. Seminário Integraclón Latínoamericana y território, Anais... Bueno Aires 1991.

SILVA, G, do C. Conjuntura política nacional: o poder executivo e geopolítica do Brasil. Rio de Janeiro: José Olympio, 1981.

SILVA, L, O. As leis agrárias e o latifúndio improdutivo. São Paulo em Perspectiva, v. 11, n. 2, São Paulo, 1997.

SILVA, S, A da. Costurando sonhos: trajetória de um grupo de imigrantes bolivianos em São Paulo. São Paulo: Paulinas, 2007. 
SOARES, F, C. Santa Thereza: um estudo sobre as charqueadas da fronteira Brasil Uruguai. Dissertação (Mestrado em Integração Latino-americana) 2006. Universidade Federal de Santa Maria, Santa Maria, 2006.

VIEIRA, E, F. e RANGEL, S, S. Geografia Econômica do Rio Grande do Sul. Porto Alegre: Sagra, 1993.

\section{NOTAS DE AUTOR}

\section{CONTRIBUIÇÃO DE AUTORIA}

Cláudia Heloiza Conte - Concepção. Coleta de dados, Análise de dados, Elaboração do manuscrito, revisão e aprovação da versão final do trabalho

\section{FINANCIAMENTO}

Não se aplica

CONSENTIMENTO DE USO DE IMAGEM

Não se aplica

\section{APROVAÇÃO DE COMITÊ DE ÉTICA EM PESQUISA}

Não se aplica

CONFLITO DE INTERESSES

Não se aplica

\section{LICENÇA DE USO}

Este artigo está licenciado sob a Licença Creative Commons CC-BY. Com essa licença você pode compartilhar, adaptar, criar para qualquer fim, desde que atribua a autoria da obra.

\section{HISTÓRICO}

Recebido em: 17-01-2019

Aprovado em: 01-03-2019 